\title{
Factors Associated with Teachers' Recruitment and Continuous Engagement of External Coaches in School-Based Extracurricular Sports Activities: A Qualitative Study
}

\author{
Kenryu Aoyagi ${ }^{1}$, Kaori Ishii ${ }^{2}$, Ai Shibata ${ }^{2}$, Hirokazu Arai ${ }^{3}$, Chisato Hibi ${ }^{1}$, Koichiro Oka ${ }^{2}$ \\ ${ }^{1}$ Graduate School of Sport Sciences, Waseda University, Saitama, Japan \\ ${ }^{2}$ Faculty of Sport Sciences, Waseda University, Saitama, Japan \\ ${ }^{3}$ Faculty of Letters, Hosei University, Tokyo, Japan \\ Email: ken-ryu.ao-yagi@ruri.waseda.jp
}

Received January $18^{\text {th }}, 2013$; revised February $20^{\text {th }}, 2013$; accepted March $4^{\text {th }}, 2013$

Copyright (C) 2013 Kenryu Aoyagi et al. This is an open access article distributed under the Creative Commons Attribution License, which permits unrestricted use, distribution, and reproduction in any medium, provided the original work is properly cited.

\begin{abstract}
School-based extracurricular sports activity (SBECSA) has developed as an opportunity that adolescents play sports in Japan. However, there are some issues to maintain active SBECSA such as lack of teacher who can coach SBECSA expertly, and large imposition of teachers to manage SBECSA. For resolving these issues, promoting engagement of external coach is favorable. Nevertheless, the number of external coach has not been enough. Therefore, the purpose of the present study was to explain facilitators and barriers related with teacher's action for recruitment and handling with external coach, and expected qualification for external coach. Personal semi-structured interview was performed toward 22 teachers who worked in a public junior high school or a public high school. In the analysis of the present study, the KJ method-a type of qualitative analyses-was used. All transcribed data were divided into individual content and grouped together into small, middle and large categories. For facilitators, four large categories such as benefits to SBECSA, benefits to teachers, system and support were emerged. For barriers, four large categories such as negative influences on SBECSA, negative influences on teachers, system and support were grouped. For expected qualifications, five large categories such as humanity, ability, cooperativeness, attributions and trust were categorized. In conclusion, the present study identified various facilitators, barriers and expected qualifications. External coach would increase by enhancing facilitators, reducing barriers, and targeting human resource who meets expected qualifications.
\end{abstract}

Keywords: Adolescent; KJ Method; Facilitator; Barrier; Expected Qualification

\section{Introduction}

Sports are regarded as necessary activities for people to lead a healthy and cultural life (Ministry of Education, Culture, Sports, Science and Technology in Japan: MEXT, 2011). School-based extracurricular sports activity (SBECSA) has been developed to provide an opportunity for adolescents to play sports. In Japan, SBECSA is performed after school and on weekends. Generally, teachers coach team members and manage the SBECSA. In 2009, $64.9 \%$ of junior high school students $(75.5 \%$ boys and $53.8 \%$ girls) and $40.7 \%$ of high school students $(54.5 \%$ boys and $26.6 \%$ girls $)$ participated in SBECSA (MEXT, 2009b). Because of large numbers of participants, SBECSA is considered to have an enormous influence on adolescents' lives. Furthermore, MEXT has emphasized that SBECSA should be closely associated with education in the Course of Study for junior high and high schools (curriculum guide for defining basic standards for education) (MEXT, 2008, 2009a).

SBECSA is a very valuable activity for healthy development of adolescents. A Japanese national-wide survey for physical fitness revealed not only a cross-sectional positive relationship between participation in SBECSA and physical fitness, but also a long-term effect of SBECSA on adult physical fitness (MEXT, 2012). Farb and Matjasko (2012) reviewed previous studies for school-based extracurricular activities and adolescent development. Some positive effects of extracurricular sports activities for academic performance, educational attainment, and psychological adjustment are revealed in the review. Thus, it is crucial for adolescents to stay active in SBECSA to gain short-term and long-term benefits.

However, there are some issues with SBECSA staying active at schools. First, some teachers are not technically able to coach the sport involved in the SBECSA at their school, even though full-time teachers generally coach SBECSA (MEXT, 1997, 2010b). According to research performed in Japan, more than half of SBECSA teachers did not have expertise to coach the sport offered at their schools (Yamagata Prefecture Board of Education, 2010). Second, SBECSA teachers are often faced with physical, monetary, and mental impositions to manage SBECSA (MEXT, 1997; Japan Senior High School Teachers and Staff Union, 2008). Third, when SBECSA teachers transfer to other schools, the SBECSA sometimes becomes inactive 
(School-based Extracurricular Sport Activity in Junior High School "Nagano Model" Exploratory Committee, 2004; Nakazawa, 2011). Generally, Japanese teachers of public school are required to transfer to another school once every several years. Given that expert coaching relates with positive youth development (e.g., improving performance skill, confidence, positive social relationship, and morality) (Cote \& Gilbert, 2009; Stewart, Lindsay, \& Trevor, 2011), expert coaches are essential in SBECSA.

To resolve these issues, there has been a growing interest from schools and government in promoting engagement of external coaches in SBECSA. An external coach is defined as a person who coaches school-based extracurricular activity instead of or support for teacher (Sasakawa Sports Foundation, 2011). For example, human resources of external coach are a part-time teacher, sport club coach, leader of a social physical education program, graduate of the school in question, and parent of the students (All Japan High School Athletic Federation, 2012). In 2010, MEXT also recommended that schools should emphasize engagement of external coaches in SBECSA (MEXT, 2010b). Actually in many cases, sports activities have been outsourced in some countries, especially extracurricular activities in Australia (Macdonald, 2011; Williams, Hay, \& Macdonald, 2011). However, engagement of external coaches in SBECSA is currently inadequate in Japan. A lack of external coaches has been reported for certain sports (e.g., wrestling and archery) (Nippon Junior High School Physical Culture Association, 2010). In addition, the number of external coaches varies greatly depending on prefectural area (Nishijima, Yano, \& Nakazawa, 2007). In such situations, teachers also reported insufficient or limited coaching frequency and difficulty securing human resources as important issues associated with recruitment and continuous engagement of external coaches (Miyagi Prefecture Board of Education, 2008; Yamagata Prefecture Board of Education, 2010).

To promote engagement of external coaches, enhancement of facilitatory factors and reduction of barriers associated with teachers' recruitment and support of external coaches would be valid strategies. In addition, to clarify how external coaches are required by teachers is important to target human resources as external coaches. However, only few Japanese and other countries' studies have examined facilitators, barriers to promoting engagement of external coaches, and qualifications expected of external coaches among full-time teachers (Miyagi Prefecture Board of Education, 2008; Yamagata Prefecture Board of Education, 2010; Williams, Hay, \& Macdonald, 2011). Additionally, most studies were conducted by quantitative methods using only few question items. Thus, previous researches may not comprehensively clarify facilitators, barriers, and expected qualifications. To identify factors associated with recruitment and continuous engagement of external coaches, qualitative research such as that involving interview is necessary. Therefore, the purposes of the present study were to clarify facilitators and barriers associated with recruitment and continuous engagement of external coaches as well as expected qualifications of external coaches among full-time school teachers.

\section{Methods}

\section{Participants}

The participants in the present study were 22 teachers who worked in either a public junior high school or a public high school. Participants were selected to vary demographic and occupational characteristics of the teachers, including type of school, prefecture, extracurricular activity type, and teaching subject. They were recruited from 13 prefectural areas, and managed 10 sports (i.e., basketball, judo, kendo, rowing, rubber-ball baseball, soccer, swimming, table tennis, tennis, and volleyball). Participants were offered a gift card worth 1000 yen for participating in the research. Participants were informed of the purpose and design of the research and written informed consent obtained from each of them. The research proposal was approved by the ethics board of Waseda University.

\section{Interview Procedure}

Before the interview, each participant's demographic and occupational characteristics were obtained in writing. A personal semi-structured interview was then performed. A pilot study was conducted with two teachers to modify the question items of the interview. The interview contained the following predetermined open-ended questions: 1) What are the facilitatory factors involved in recruiting and handling external coaches? 2) What are the barriers to recruiting and handling external coaches? 3) What qualifications do you expect of external coaches? Participants were asked to respond freely to the questions. Interview length ranged between 20 and 60 minutes. All interviews were performed at a convenient place for each participant, such as a community center or school, between June and August 2011. All interviews were audiotaped with agreement from the participants.

\section{Analysis}

The KJ method (Kawakita, 1970) was selected for analysis of the present study. The KJ method is one of qualitative analysis and it is erected by Jiro Kawakita in Japan. Adaptive possibility of this method in foreign countries has been indicated (Scupin, 1997). Before the analysis, each recorded interview was transcribed verbatim. All transcribed data were then divided into individual content by three researchers who were experts in sports education or psychology. Nearly identical contents were grouped together and corded as "small categories" in each area (i.e., facilitator, barrier, and expected qualification). For each small category, three researchers discussed and defined title of category. Next, similar small categories were further grouped into "middle categories". Finally, the similarities and differences among the middle categories produced "large categories". In a way similar to small category, each middle and large category was entitled. Then, initial of facilitator, barrier, and expected qualification with identical number was added to make discussion easier.

\section{Results}

\section{Characteristics of Participants}

Twenty-two teachers participated in the interview (Table 1). Fourteen teachers were male, and the age of the participants ranged from 24 to 58 years with an average of 41.3 years (standard deviation $=11.7)$. Eleven teachers worked in a junior high school. Only three of six SBECSA teachers who recruited external coaches provided some compensation. Teachers specialized not only in physical education, but also in other subjects 
Table 1.

Demographic and occupational characteristics of participants.

\begin{tabular}{|c|c|c|c|c|c|c|c|c|c|}
\hline No. & Gender & Age & School & Prefecture & $\begin{array}{l}\text { Extracurricular } \\
\text { activity type }\end{array}$ & Teaching subject & Status & $\begin{array}{l}\text { External coach } \\
\text { for } \\
\text { the SBECSA }\end{array}$ & Compensation \\
\hline 1 & M & 27 & Junior high & Shiga & Soccer & Health and physical education & - & No & - \\
\hline 2 & M & 29 & Junior high & Tokyo & Rubber-ball baseball & Math & - & No & - \\
\hline 3 & M & 33 & Junior high & Okinawa & Rubber-ball baseball & Japanese & - & Yes & No \\
\hline 4 & M & 35 & High & Saitama & Soccer & Math & - & Yes & Yes \\
\hline 5 & M & 38 & Junior high & Okinawa & Soccer & Math & - & No & - \\
\hline 6 & M & 42 & High & Akita & Kendo & Math and information & - & No & - \\
\hline 7 & M & 48 & High & Niigata & Volleyball & Math & - & Yes & No \\
\hline 8 & M & 49 & Junior high & Fukuoka & Brass band & Society & - & Yes & Yes \\
\hline 9 & M & 49 & High & Niigata & Swimming & Health and physical education & - & No & - \\
\hline 10 & M & 52 & High & Akita & Judo & Health and physical education & - & No & - \\
\hline 11 & M & 55 & High & Kanagawa & Rowing & Health and physical education & - & No & - \\
\hline 12 & M & 56 & Junior high & Hokkaido & - & English & Principal & - & - \\
\hline 13 & M & 57 & Junior high & Aichi & - & Art & Principal & - & - \\
\hline 14 & M & 58 & High & Hyogo & - & Health and physical education & Assistant principal & - & - \\
\hline 15 & $\mathrm{~F}$ & 24 & High & Chiba & Tennis & Math & - & No & - \\
\hline 16 & $\mathrm{~F}$ & 26 & Junior high & Hokkaido & Volleyball & Health and physical education & - & No & - \\
\hline 17 & $\mathrm{~F}$ & 26 & Junior high & Nagano & Table tennis & English & - & Yes & Yes \\
\hline 18 & $\mathrm{~F}$ & 31 & Junior high & Aichi & Basketball & Math & - & Yes & Yes \\
\hline 19 & $\mathrm{~F}$ & 31 & High & Chiba & Soccer & Health and physical education & - & No & - \\
\hline 20 & $\mathrm{~F}$ & 41 & High & Akita & Cooking & Home economics & - & - & - \\
\hline 21 & $\mathrm{~F}$ & 48 & High & Kanagawa & Volleyball & Health and physical education & - & Yes & No \\
\hline 22 & $\mathrm{~F}$ & 54 & Junior high & Fukuoka & - & Technology and home economics & Principal & - & - \\
\hline
\end{tabular}

such as math, Japanese, art, and English. Three principals and one assistant principal were also included among the participants.

\section{Facilitators}

Four large categories of facilitators emerged (Table 2). The large categories were 1) benefits to SBECSA (e.g., growth of team members, enhancement of connection with local community, prevention of decline in coaching level by changes of SBECSA teachers); 2) benefits to teachers (e.g., reduced burden on SBECSA teachers, lack of teachers who can technically coach, growth of SBECSA teachers); 3) system (e.g., compensation, mediation of external coaches); and 4) support (e.g., introduction from acquaintances, understanding from the school). There were 17 middle categories and 50 small categories for more detail in Table 2.

\section{Barriers}

Four large categories of barriers emerged (Table 3). The large categories were 1) negative influences on SBECSA (e.g., disregard of educational aspect, problem behavior, conflict of coaching policy); 2) negative influences on teachers (e.g., increased burden on SBECSA teachers, inverted status, declination of teacher's leadership ability); 3) system (e.g., lack of compensation, limitations of system, lack of cognition about system); and 4) support (e.g., opposition from others, lack of knowledge). There were 17 middle categories and 45 small categories for more detail in Table 3.

\section{Expected Qualifications}

Five large categories of expected qualifications emerged (Table 4). The large categories were 1) humanity (e.g., character, abidance by rules, educational thinking); 2) ability (e.g., credentials, technical coaching, experience); 3) cooperativeness (e.g., communication skill, support of SBECSA teachers); 4) attributions (e.g., age, occupation); 5) trust (e.g., acquaintances, selection by SBECSA teacher). There were 14 middle categories and 52 small categories for more detail in Table 4.

\section{Discussion}

To explain the facilitators and barriers of recruiting and handling relationships with external coaches and the qualifications of external coaches expected by teachers, the personal semistructured interview was administered to 22 teachers. As a result, many novel categories were extracted and categorized in the present study.

In middle category level, growth of team members, inspiring morale of team members, improvement of practice quality, enhancement of connection with local community, growth of SBECSA teachers as facilitators, and poor relationship, conflict 


\section{K. AOYAGI ET AL.}

Table 2.

Facilitators of recruitment and handling of external coaches.

\begin{tabular}{|c|c|c|}
\hline Large category (4) & Middle category (17) & Small category $(50)$ \\
\hline \multirow{27}{*}{ Benefits to SBECSA } & \multirow{7}{*}{ Growth of team members } & f1. Improving technic of team members \\
\hline & & f2. Team member contact with adults other than teacher \\
\hline & & f3. Learning about manners \\
\hline & & f4. Positive effect on mental phase \\
\hline & & $\begin{array}{l}\text { f5. Showing communication with SBECSA teacher and } \\
\text { external coach to team members }\end{array}$ \\
\hline & & f6. Desire to let team members more skillful \\
\hline & & f7. Ease of teaching team members courtesy toward external coach \\
\hline & \multirow{7}{*}{ Inspiring morale of team members } & f8. Increasing motivation of team members \\
\hline & & f9. Increasing confidence of team members \\
\hline & & f10. Providing stimulation for team members \\
\hline & & f11. Having freshness for daily SBECSA \\
\hline & & f12. Bracing climate of the SBECSA \\
\hline & & f13. Conveying enthusiasm about the sport \\
\hline & & f14. Conveying expectations of SBECSA teacher to team members \\
\hline & \multirow{4}{*}{ Improvement of practice quality } & f15. Growing in practice efficiency \\
\hline & & f16. Having a diverse coaching method \\
\hline & & f17. Being able to show examples of play \\
\hline & & f18. Increasing practice method \\
\hline & \multirow{3}{*}{ Enhancement of connection with local community } & f19. Utilizing a human network of external coaches \\
\hline & & f20. Connection with local community \\
\hline & & f21. Utilizing human resources of local community \\
\hline & \multirow{2}{*}{ Improvement of safety } & f22. Improvement of safety \\
\hline & & f23. Dealing with members' injuries \\
\hline & \multirow[b]{2}{*}{$\begin{array}{l}\text { Prevention of decline in coaching level by changes } \\
\text { of SBECSA teachers }\end{array}$} & f24. Maintaining coaching level when SBECSA teacher changes schools \\
\hline & & $\begin{array}{l}\text { f25. Ease of fit the SBECSA which has external coach when } \\
\text { teacher changes schools }\end{array}$ \\
\hline & Improvement of cogency & f26. Having cogency \\
\hline & Coordination between SBECSA teacher and parents & f27. Becoming a bridge between SBECSA teacher and parents \\
\hline \multirow{16}{*}{ Benefits to teachers } & \multirow{6}{*}{ Reduced burden on SBECSA teachers } & f28. Reduced burden on SBECSA teacher \\
\hline & & f29. Help for SBECSA teacher \\
\hline & & f30. Being able to use time other than that spent on technical coaching \\
\hline & & f31. Increasing number of coaches \\
\hline & & f32. No need for SBECSA teacher to learn about the sport \\
\hline & & f33. Being able to allow the SBECSA teacher to rest \\
\hline & \multirow{4}{*}{ Lack of teachers who can technically coach } & f34. Inability of SBECSA teacher to coach technically \\
\hline & & f35. No teachers available to become an SBECSA teacher \\
\hline & & f36. Worry for team members because of no technical coaching \\
\hline & & $\begin{array}{l}\text { f37. Complaints from team members regarding SBECSA teacher } \\
\text { who cannot coach technically }\end{array}$ \\
\hline & \multirow{3}{*}{ Coaching from various perspectives } & f38. Having other viewpoints \\
\hline & & f39. Closeness of external coach with team members \\
\hline & & f40. Seeing growth of team members in terms of the SBECSA \\
\hline & \multirow{2}{*}{ Growth of SBECSA teachers } & f41. Promoting SBECSA teacher's learning about coaching methods \\
\hline & & f42. Promoting SBECSA teacher's learning about attitude toward team members \\
\hline & Busyness of teacher & f43. Teachers' busyness of their work \\
\hline \multirow{4}{*}{ System } & \multirow{3}{*}{ Compensation } & f44. System that supplies external coach with compensation \\
\hline & & f45. Increasing adoptable number of external coaches in system \\
\hline & & f46. Ease of prescribing to external coach because of supplied compensation \\
\hline & Mediation of external coaches & f47. System that mediates external coaches \\
\hline \multirow{3}{*}{ Support } & \multirow{2}{*}{ Introduction from acquaintances } & f48. Availability of person to introduce external coach \\
\hline & & f49. Strong connection with relatives \\
\hline & Understanding from the school & f50. Positive attitude of school regarding engagement of external coach \\
\hline
\end{tabular}

Note: "f" placed in front of small category means "facilitator". Additionally, each small category was given identical number for discussion. 


\section{K. AOYAGI ET AL.}

Table 3.

Barriers to recruitment and handling of external coaches.

\begin{tabular}{|c|c|c|}
\hline Large category (4) & Middle category (17) & Small category (45) \\
\hline \multirow{16}{*}{$\begin{array}{l}\text { Negative influences } \\
\text { on SBECSA }\end{array}$} & \multirow{5}{*}{ Poor relationship } & b1. Past failure to engage external coach \\
\hline & & b2. Having trouble with parents \\
\hline & & b3. Development of a complex human relationship \\
\hline & & b4. Break up of relationship between external coach and team members \\
\hline & & b5. Mismatch of SBECSA teacher and external coach \\
\hline & \multirow{4}{*}{ Disregard of educational aspect } & b6. External coach who cannot give pupils guidance \\
\hline & & b7. Lack of understanding of external coach about school policy \\
\hline & & b8. Lack of knowledge about team member's life in school \\
\hline & & b9. Too much value placed on winning \\
\hline & \multirow{4}{*}{ Problem behavior } & b10. Physical punishment \\
\hline & & b11. Sexual harassment \\
\hline & & b12. Ranting \\
\hline & & b13. Misappropriating \\
\hline & \multirow{2}{*}{ Conflict of coaching policy } & b14. Conflicting opinions with external coach \\
\hline & & b15. Becoming practice of SBECSA harder \\
\hline & Insufficient technical coaching & b16. Developing a way to resolve immobilization of the external coach \\
\hline \multirow{12}{*}{$\begin{array}{l}\text { Negative influences } \\
\text { on teachers }\end{array}$} & \multirow{5}{*}{ Increased burden on SBECSA teachers } & b17. Increased burden on SBECSA teacher \\
\hline & & b18. Attentiveness to external coach \\
\hline & & b19. Feeling sorry for external coach because the SBECSA was not managed well \\
\hline & & b20. Burden of only seeing external coach's coaching \\
\hline & & b21. The need to try hard if external coach engages in SBECSA \\
\hline & \multirow{3}{*}{$\begin{array}{l}\text { Decreased coaching opportunity } \\
\text { for teacher }\end{array}$} & b22. Availability of teacher who can technically coach the sport \\
\hline & & b23. Feeling of not having to depend on external coach \\
\hline & & b24. Loss of enjoyment of coaching \\
\hline & \multirow{2}{*}{ Difficulty adjusting to external coach } & b25. Inconvenient practice time \\
\hline & & b26. No time for meetings \\
\hline & Inverted status & b27. Stronger influence of external coach than SBECSA teacher on team members \\
\hline & Declination of teacher's leadership ability & b28. Declination of teacher's leadership ability \\
\hline \multirow{13}{*}{ System } & \multirow{5}{*}{ Rudimentary system } & b29. Difficulty to cancel the engagement of external coach once engaged in SBECSA \\
\hline & & b30. Cumbersome procedure to enroll external coach \\
\hline & & b31. Unclear system of introduction of external coaches \\
\hline & & b32. Uncertain system \\
\hline & & b33. Large burden on external coach \\
\hline & \multirow{3}{*}{ Lack of compensation } & b34. Little compensation \\
\hline & & $\begin{array}{l}\text { b35. Difficulty prescribing to external coach because of a lack } \\
\text { of compensation (volunteer) }\end{array}$ \\
\hline & & b36. Burden of compensation \\
\hline & \multirow{2}{*}{ Limitations of system } & b37. Institutional limitation on number of external coaches \\
\hline & & b38. Institutional limitation on coaching frequency \\
\hline & \multirow{2}{*}{ Lack of cognition about system } & b39. Little knowledge of system \\
\hline & & b40. Lack of dissemination of system \\
\hline & Difficulty finding external coaches & b41. Difficulty finding external coaches \\
\hline \multirow{4}{*}{ Support } & \multirow{2}{*}{ Opposition from others } & b42. Negative attitude of school regarding engagement of external coach \\
\hline & & b43. Opposition to accepting external coaches who live outside of the local area \\
\hline & \multirow{2}{*}{ Lack of knowledge } & b44. Having had no ideas to promote engagement of external coach \\
\hline & & b45. Ignorance about engagement of external coach in the school \\
\hline
\end{tabular}

Note: "b" placed in front of small category means "barrier". Additionally, each small category was given identical number for discussion. 


\section{K. AOYAGI ET AL.}

Table 4.

Expected qualifications of external coaches by teachers.

\begin{tabular}{|c|c|c|}
\hline Large category (5) & Middle category (14) & Small category (52) \\
\hline \multirow{18}{*}{ Humanity } & \multirow{8}{*}{ Character } & e1. A person of integrity \\
\hline & & e2. Being trusted by team members \\
\hline & & e3. Having passion \\
\hline & & e4. Having general intelligence \\
\hline & & e5. A person who likes children \\
\hline & & e6. Cheerful disposition \\
\hline & & e7. A person who does not hide anything \\
\hline & & e8. A person who likes sports \\
\hline & \multirow{5}{*}{ Abidance by rules } & e9. No physical punishment \\
\hline & & e10. Staying on time \\
\hline & & e11. No sexual harassment \\
\hline & & e12. Having clear boundaries with team members \\
\hline & & e13. Abiding by a duty of secrecy \\
\hline & \multirow{4}{*}{ Educational thinking } & e14. Thinking of the personal progress of team members \\
\hline & & e15. Understanding that SBECSA is a school activity \\
\hline & & e16. Not only engaging in technical coaching \\
\hline & & e17. Not only valuing winning \\
\hline & No business use & e18. Not using status of external coach in other business \\
\hline \multirow{13}{*}{ Ability } & \multirow{6}{*}{ Expert } & e19. Expert in physical training \\
\hline & & e20. Expert with a high level technique and coach in the short-term \\
\hline & & e21. Ability to perform acupuncture or massage \\
\hline & & e22. Expert in mental training \\
\hline & & e23. A person who can engage more than one SBECSA \\
\hline & & e24. Expert in nutritional guidance \\
\hline & \multirow{3}{*}{ Credentials } & e25. Taken a course in coaching \\
\hline & & e26. Having credentials for coaching \\
\hline & & e27. Having teaching credentials \\
\hline & \multirow{2}{*}{ Technical coaching } & e28. Being able to coach technically \\
\hline & & e29. Having knowledge about technical coaching theory \\
\hline & \multirow{2}{*}{ Experience } & e30. Having experience in coaching \\
\hline & & e31. Having experience in teaching \\
\hline \multirow{8}{*}{ Cooperativeness } & \multirow{4}{*}{ Communication skill } & e32. Being able to communicate with others \\
\hline & & e33. Fit of coaching policy with SBECSA teacher \\
\hline & & e34. Not coaching only by the external coach's opinion \\
\hline & & e35. Ability to communicate opinions to SBECSA teacher \\
\hline & \multirow{4}{*}{ Support of SBECSA teachers } & e36. Being an adjunct of SBECSA teacher \\
\hline & & e37. Coaching regularly \\
\hline & & e38. Becoming a bridge between SBECSA teacher and team members \\
\hline & & e39. Giving main position to SBECSA teacher \\
\hline \multirow{7}{*}{ Attributions } & \multirow{4}{*}{ Age } & e40. Young \\
\hline & & e41. Age from 30 s to $40 \mathrm{~s}$ \\
\hline & & e42. Elderly \\
\hline & & e43. Younger than SBECSA teacher \\
\hline & \multirow{3}{*}{ Occupation } & e44. Civil servant \\
\hline & & e45. A person whose job is coaching SBECSA \\
\hline & & e46. Sport store staff \\
\hline \multirow{6}{*}{ Trust } & \multirow{5}{*}{ Acquaintances } & e47. Pupil the teacher once taught \\
\hline & & e48. Introduction from acquaintance \\
\hline & & e49. Understanding the character of the person \\
\hline & & e50. Graduate student of the school \\
\hline & & e51. Parent of the team members \\
\hline & Selection by SBECSA teacher & e52. Selection by SBECSA teacher \\
\hline
\end{tabular}

Note: "e" placed in front of small category means "expected qualification". Additionally, each small category was given identical number for discussion. 
of coaching policy, difficulty adjusting to external coach, lack of compensation, difficulty finding external coaches as barriers were consist with previous researches (Ibaraki Prefecture Sports Promotion Council, 2007; Yamagata Prefecture Board of Education, 2010; Williams, Hay, \& Macdonald, 2011). In the facilitator for benefits to SBECSA, growth of team members was categorized (for example, "fl. improving technic of team members", " $\mathrm{f} 2$. team member contact with adults other than teacher", and "f3. learning about manners"). Especially for "f2. team member contact with adults other than teacher", pupil guidance recommendations published by MEXT indicated that communication with local adults or coaches improves sociality and norm consciousness of children (MEXT, 2010a). Therefore, external coaches have positive effect for socialization of children. Additionally, activity with peers and adults cause higher intrinsic motivation of children than activity with peers only (Shernoff \& Vandell, 2007). The result of the present study (i.e., "f8. Increasing motivation of team members" in benefits to SBECSA) also demonstrated that there are some cases which recruitment of external coach increases motivation of team members.

However, disregard of educational aspects (e.g., "b6. external coach who cannot give pupils guidance" and "b9. too much value placed on winning") and problem behavior (e.g., "b10. physical punishment" and "b12. ranting") that could have negative influences on SBECSA were categorized as barriers. In addition, educational thinking by the external coach (e.g., "e14. thinking of the personal progress of team members", "e16. not only engaging in technical coaching", and "e17. not only valuing winning") was reported in humanity as an expected qualification. It is suggested that selecting or providing an external coach who has an educational attitude helps teachers to accept external coaches and reduce future trouble with the coaching policy between teachers and external coaches.

For system among both facilitators and barriers, factors related to understanding from the school were observed (e.g., "f50. positive attitude of school regarding engagement of external coach" was a facilitator, and "b42. negative attitude of school regarding engagement of external coach" was a barrier). In most situations, school principals have the authority to determine the school's management policy. Therefore, if the school principal opposes the recruitment of an external coach, it is very difficult for a teacher to recruit the external coach. Encouraging cognition of school principal for the benefits of recruiting external coaches clarified in the present study would facilitate engagement of external coaches.

In the system of barrier, "b31. unclear system of introduction of external coaches" was revealed. A previous case study, aimed to develop a mediation system of external coach, similarly indicated that insufficient disclosure of information disturbed promotion of engagement of external coaches (Kanagawa Prefectural Center of Physical Education, 2007; Okatsu, 2011). Disclosing information about external coaches is important to enhance teachers' accessibility to the mediation system. Insufficient disclosure of information could relate to trust of external coaches categorized as a large category of expected qualifications. Teachers required acquaintances such as "e47. pupil the teacher once taught", "e50. graduate student of the school", and "e51. parent of the team members". Previous studies also reported that most SBECSA teachers selected external coaches from acquaintances of the teacher or former students of the school because it was easier to obtain their in- formation and they could trust these individuals more than an unknown person (Kanagawa Prefectural Center of Physical Education, 2007; Okatsu, 2011). To increase trust of external coaches, obtaining their personal information is necessary. Thus, promoting transparency of information (e.g., coaching policy or how external coaches are introduced) is crucial when organizations that manage mediation systems of external coaches, such as prefectural boards of education, modify the mediation system.

Among the other barriers in system, lack of cognition about system (for details, "b39. little knowledge of system" and "b40. lack of dissemination of system") were notable. Research in Kanagawa prefecture explained that most external coaches, teachers, and principals did not know about the coach mediation system of Kanagawa prefecture (Kanagawa Prefectural Center of Physical Education, 2007; Kanagawa Prefecture Board of Education, 2008). Thus, it is important that the local government which manages the coach mediation system develops effective strategies with which to advertise the system to the school and to each teacher to promote engagement of the external coach.

As negative influences on teachers, inverted status (i.e., "b27. stronger influence of external coach than SBECSA teacher on team members") was identified. In SBECSA management guide of Ehime prefecture, disrespect for the SBECSA teacher by team members was reported as an issue arising from excessive dependence of the SBECSA teacher on the external coach (Ehime Prefecture Board of Education, 2011). To avoid disrespect for SBECSA teachers by team members, cooperativeness such as "e34. not coaching only by the external coach's opinion", "e36. being an adjunct of SBECSA teacher", and "e39. giving main position to SBECSA teacher" were interpreted as expected qualifications. As a way, clearly defining the position and roles of the external coach would enhance teachers' actions in recruiting external coaches.

In terms of expected qualifications, there were various opinions regarding the age group of external coaches in attributions. The study for Slovene coaches mentioned that younger coaches were more accurate, open to novelties, conscious, agreeable, and able to manage their own emotions compared with older coaches. Whereas, older coaches behaved in a more democratic manner than did younger coaches (Dimec \& Kajtna, 2009). Because characteristics of each coaching method differ depending on the age of the coach, the teachers examined in the present study explained their preferred coaching method characteristics of external coaches in terms of age group.

In addition, there were different opinions regarding teachers' burdens, such as "f28. reduced burden on SBECSA teacher" in benefits to teachers versus "b17. increased burden on SBECSA teacher" in negative influences on teachers. Recognition of teachers by providing compensation in system, both of facilitator and barrier, also differed (e.g., "f46. ease of prescribing to external coach because of supplied compensation" as a facilitator versus "b35. difficulty prescribing to external coach because of a lack of compensation (volunteer)" as a barrier). Some local governments have established a system of supplying compensation, although many local governments do not have a mediation and compensation supply system (Setagaya Ward Board of Education, 2009). This explains the regional difference and teachers' personal differences in the factors associated with recruitment and handling of external coaches.

A limitation of the present study is that SBECSA or 
SBECSA teacher characteristics and regional characteristics are not differentiated. Future studies must specify the relationship between the characteristics of SBECSA and teacher and the categories of facilitator, barrier, and expected qualification. While there are limitations, the present study extracted and categorized many novel facilitators, barriers, and expected qualifications related to the behavior of teachers in recruiting and handling external coaches. The participants in the present study had rich characteristic variation (e.g., type of school, prefectures located in urban and rural areas, extracurricular activity type, and teaching subject). The diversity of participants helped to collect exhaustive opinions from teachers, and expand adoptive possibility for other prefectures in Japan or other countries faced similar problems such as lack of coach.

\section{Conclusion}

The present study identified various and detailed facilitators and barriers associated with the recruitment and continuous engagement of external coaches, as well as the expectation of their qualifications. According to the result of the present study, it is suggested that the local government which manages the coach mediation system should promote transparency of external coaches' information and develop strategies with which to advertise the system to the school and teachers. Similarly, encouraging cognition of school principal for the benefits of recruiting external coaches clarified in the present study would be valuable. As a further suggestion, selecting or providing external coaches who have an educational attitude and defining the positions and roles of external coaches clearly helps teachers to accept them and reduce future trouble with coaching policies between teachers and external coaches. Promoting engagement of external coaches would be made easier by enhancing facilitators and ridding barriers associated with recruitment and handling of external coaches as well as targeting human resources who meet expected qualifications. The findings of the present study may contribute to promote engagement of appropriate external coaches, and could provide one of clues to resolve issues of SBECSA commencing with lack of coach, and achieves further youth development.

\section{Acknowledgements}

The authors would like to thank all participating teachers and the peers who introduced participants. The present study was supported by the Sasakawa Sports Research Grant (No. 120B3-010) from Sasakawa Sports Foundation, and Global COE Program "Sport Sciences for the Promotion of Active Life" from the Ministry of Education, Culture, Sports, Science and Technology in Japan.

\section{REFERENCES}

All Japan High School Athletic Federation (2012). News from head office. URL (last checked 17 January 2013).

$\mathrm{http}: / /$ www.zen-koutairen.com/f_publish.html

Cote, J., \& Gilbert, W. (2009). An integrative definition of coaching effectiveness and expertise. International Journal of Sports Science and Coaching, 4, 307-322. doi:10.1260/174795409789623892

Dimec, T., \& Kajtna, T. (2009). Psychological characteristics of younger and older coaches. Kinesiology, 41, 172-180.

Ehime Prefecture Board of Education (2011). Management guide of school-based extracurricular sport activity. URL (last checked 17
January 2013).

http://ehime-c.esnet.ed.jp/hosupo/undoubukatudou/index.html

Farb, F. A., \& Matjasko, L. J. (2012). Recent advances in research on school-based extracurricular activities and adolescent development. Developmental Review, 32, 1-48. doi:10.1016/j.dr.2011.10.001

Ibaraki Prefecture Sports Promotion Council (2007). The way of future school-based extracurricular sport activity. URL (last checked 17 January 2013).

http://www.edu.pref.ibaraki.jp/board/bunspo/sports/setti/toushin.pdf

Japan Senior High School Teachers and Staff Union (2008). Final report of actual condition survey for issues of school-based extracurricular sport activity in 2006.

Kanagawa Prefectural Center of Physical Education (2007). As regards a way of future system of registration and mediation of coach. URL (last checked 17 January 2013). http://www.pref.kanagawa.jp/uploaded/attachment/2426.pdf

Kanagawa Prefecture Board of Education (2008). Research report for sport activity of secondary school student. URL (last checked 17 January 2013). http://www.pref.kanagawa.jp/uploaded/attachment/176796.pdf

Kawakita, J. (1970). Zoku hassouhou. Tokyo: Chuokoron-shinsha, Inc.

Macdonald, D. (2011). Like a fish in water: Physical education policy and practice in the era of neoliberal globalization. Quest, 63, 36-45.

Ministry of Education, Culture, Sports, Science and Technology in Japan (1997). Report of investigative research for way of schoolbased extracurricular sport activity. URL (last checked 17 January 2013).

http://www.mext.go.jp/b_menu/shingi/chousa/sports/001/toushin/971 201.htm

Ministry of Education, Culture, Sports, Science and Technology in Japan (2008). The course of study in junior high school. URL (last checked 17 January 2013).

http://www.mext.go.jp/a_menu/shotou/new-cs/youryou/1304424.htm

Ministry of Education, Culture, Sports, Science and Technology in Japan (2009a). The course of study in higher school. URL (last checked 17 January 2013).

http://www.mext.go.jp/a_menu/shotou/new-cs/youryou/1304427.htm

Ministry of Education, Culture, Sports, Science and Technology in Japan (2009b). White paper on education, culture, sports, science and technology. URL (last checked 17 January 2013). http://www.mext.go.jp/b_menu/hakusho/html/hpab200901/1295623. $\mathrm{htm}$

Ministry of Education, Culture, Sports, Science and Technology in Japan (2010a). Outline of pupil guidance. Tokyo: Kyoiku-tosho, Co., Ltd.

Ministry of Education, Culture, Sports, Science and Technology in Japan (2010b). Sport-oriented nation strategy: Sport community Japan. URL (last checked 17 January 2013). http://www.mext.go.jp/a_menu/sports/rikkoku/1297182.htm

Ministry of Education, Culture, Sports, Science and Technology in Japan (2011). Basic law of sports. URL (last checked 17 January 2013).

http://www.mext.go.jp/a_menu/sports/kihonhou/attach/1307658.htm

Ministry of Education, Culture, Sports, Science and Technology in Japan (2012). National survey result of physical and athletic capacity. URL (last checked 17 January 2013).

http://www.mext.go.jp/b_menu/toukei/chousa04/tairyoku/kekka/k_d etail/1326589.htm

Miyagi Prefecture Board of Education (2008). Research for schoolbased extracurricular sport activity of secondary school.

Nakazawa, A. (2011). A postwar history of extracurricular sport activities in Japan (1): Focusing on the transition of the actual situation and policy. Hitotsubashi Bulletin of Social Sciences, 3, 25-46.

Nippon Junior High School Physical Culture Association (2010). Spread sheet of research for number of member school and student. URL (last checked 17 January 2013). http://www18.ocn.ne.jp/ njpa/pdf/h22gaibu2_mf.pdf

Nishijima, H., Yano, H., \& Nakazawa, A. (2007). A sociological study of coaching and management of club activities in junior high schools: Based on a questionnaire survey to teachers of sports club activities in two prefectures and Tokyo metropolitan. Bulletin of Faculty of 
Education in the University of Tokyo, 47, 101-130.

Okatsu, S. (2011). Way of utilizing local human resource in SBECSA: Challenge of SBECSA external coach in Nagoya. Toho Gakushi, 40, 35-46. URL (last checked 17 January 2013).

http://www.aichi-toho.ac.jp/outline/files/201106004001_03.pdf

Sasakawa Sports Foundation (2011). Installation of sports leader bank in each prefecture. Sports White Paper: Future that Sports Should to Aspire, 86-88.

School-Based Extracurricular Sport Activity in Junior High School "Nagano Model" Exploratory Committee (2004). Proposal of schoolbased extracurricular sport activity in junior high school "Nagano model". URL (last checked 17 January 2013).

http://www.pref.nagano.lg.jp/kyouiku/taiiku/bukatu/teigen/teigen.pdf

Scupin, R. (1997). The KJ method: A technique for analyzing data derived from Japanese ethnology. Human Organization, 56, 233-237.

Setagaya Ward Board of Education (2009). "Support of SBECSA, detachment of school councilor" in Setagaya ward. URL (last checked 17 January 2013).

http://www.mext.go.jp/b_menu/shingi/chukyo/chukyo3/042/siryo/_i csFiles/afieldfile/2009/03/19/1247451_4

Shernoff, J. D., \& Vandell, L. D. (2007). Engagement in after-school program activities: Quality of experience from the perspective of participants. Journal of Youth and Adolescence, 36, 891-903. doi:10.1007/s10964-007-9183-5

Stewart, V., Lindsay, O., \& Trevor, C. (2011). The role of the coach in facilitating positive youth development: Moving from theory to practice. Journal of Applied Sport Psychology, 23, 33-48. doi:10.1080/10413200.2010.511423

Tokyo Metropolitan Board of Education (2008). Companion of coaching school-based extracurricular activity for external coach. URL (last checked 17 January 2013).

http://www.kyoiku.metro.tokyo.jp/press/bukatsu_tebiki.pdf

Williams, J. B., Hay, J. P., \& Macdonald, D. (2011). The outsourcing of health, sport and physical educational work: A state of play. Physical Education and Sport Pedagogy, 16, 399-415.

doi:10.1080/17408989.2011.582492

Yamagata Prefecture Board of Education (2010). As regards a way of future school-based extracurricular sport activity. URL (last checked 17 January 2013).

http://www.pref.yamagata.jp/ou/kyoiku/700021/21 unndoubukatudou arikata.pdf 